\title{
IMPLEMENTASI METODE AL-HUSNA SEBAGAI ALTERNATIF PENGENALAN HURUF HIJAIYAH
}

\section{THE IMPLEMENTATION OF THE AL-HUSNA METHOD AS AN ALTERNATIVE TO INTRODUCE HIJAIYAH LETTERS}

\author{
Amarizki Purwa Kusuma1), Mudhofir Abdullah' \\ 1,2)IAIN Surakarta \\ amarizkipurwakusuma@gmail.com ${ }^{11}$, mudhofir1527@gmail.com²)
}

\begin{abstract}
Abstrak
Tujuan penelitian ini adalah mengetahui implementasi penggunaan metode Al-Husna dalam mengenalkan huruf hijaiyah. Penelitian ini menggunakan penelitian deskriptif kualitatif. Sumber data diperoleh melalui observasi, wawancara dan dokumentasi. Data yang terkumpul dianalisis dengan menggunakan teknik analisis model Miles dan Huberman terdiri dari pengumpulan data, reduksi data, penyajian dan penarikan kesimpulan. Hasil penelitian menunjukkan metode Al Husna digunakan agar pembelajaran dalam membaca Al-Qur'an menjadi lebih mudah, praktis, sistematis serta berpedoman pada pengajaran Rasulullah SAW kepada para sahabatnya yaitu dengan memakai penulisan rasm utsmani dan teruji keasliannya. Implementasi penerapan metode Al Husna di KB/TK MTA Jebres terdiri dari beberapa tahapan yang meliputi persiapan, pelaksanaan dan penilaian. Tahap persiapan yang dilakukan seperti penyiapan ruang kelas, media dukung dan RPPH. Tahap selanjutnya yaitu pengaplikasian metode Al Husna dalam mengenalkan huruf hijaiyah dilakukan dengan cara sistem urutan, scanning dan kata kunci, dan yang terakhir cara menulisnya. Tahap terakhir adalah penilaian yang dilakukan dengan menulis hasil belajar anak di kartu prestasi dan pemberian reward berupa bintang di tangan menggunakan spidol agar lebih semangat. Kesimpulannya penggunaan metode Al-Husna dapat membantu anak lebih cepat dalam memahami huruf hijaiyah sejak dini.
\end{abstract}

Kata Kunci: implementasi, metode Al-Husna, huruf hijaiyah

\begin{abstract}
The purpose of this research is to know the implementation of the use of Al-Husna method in introducing the letter Hijaiyah. This research uses descriptive qualitative research. Data sources are obtained through observation, interviews and documentation. The collected data is analyzed using Miles and Huberman model analysis techniques consisting of data collection, data reduction, presentation and inference. The results showed that Al Husna method is used so that learning in reading the Qur'an becomes easier, practical, systematic and based on the teaching of the Prophet muhammad to his friends by using ottoman rasm writing and tested its authenticity. Implementation of Al Husna method in KB/TK MTA Jebres consists of several stages which include preparation, implementation and assessment. The preparation stages are carried out such as classroom preparation, support media and RPPH. The next step is the application of Al Husna method in introducing hijaiyah letters by means of sequence system, scanning and keywords, and the last way to write it. The last stage is the assessment done by writing the children's learning results on the achievement card and rewarding the stars in hand using markers to be more energetic. In conclusion, the use of AlHusna method can help children to understand Hijaiyah letters faster from an early age.
\end{abstract}

Keywords: implementation, Al-Husna method, hijaiyah letter 
How to Cite: Kusuma, A. P. \& Abdullah, M. (2020). Implementasi metode Al-Husna sebagai alternatif pengenalan huruf hijaiyah. Al asma: Journal of Islamic Education, 2(2), 296-303.

\section{PENDAHULUAN}

Pendidikan bagi kehidupan manusia merupakan kebutuhan mutlak yang harus dipenuhi sepanjang hayat. Tanpa adanya pendidikan, mustahil suatu kelompok manusia dapat hidup berkembang sejalan dengan cita-citanya untuk bisa maju, sejahtera dan bahagia. Pendidikan sebagai salah satu sektor yang paling penting dalam pembangunan nasional karena berfungsi untuk meningkatkan kualitas hidup manusia. Pendidikan yang baik harus diajarkan kepada anak sedini mungkin.

Pendidikan anak usia dini atau biasa disebut PAUD sedang menjadi titik perhatian masyarakat. Berbagai macam manfaat yang dapat diperoleh anak-anak ketika diberikan stimulasi sedini mungkin di PAUD dapat menarik hati masyarakat sekitar. Menurut Hasan (2010) usia dini merupakan usia emas bagi anak, pada usia tersebut anak mengalami masa yang mulai peka untuk menerima suatu rangsangan dari luar, sehingga pembelajaran untuk anak dibuat menjadi senyaman mungkin dan menyenangkan.

Ruang lingkup pendidikan anak usia dini salah satunya adalah pendidikan di taman kanak-kanak. Menurut Wiyani (2014) taman kanak- kanak merupakan tempat untuk mengenalkan sesuatu hal ataupun pembelajaran untuk anak usia 4-6 tahun. Di taman kanak-kanak biasanya terdapat dua kelompok yaitu kelompok A dengan usia 4-5 tahun dan kelompok B dengan usia 5-6 tahun. Pembelajaran di taman kanak-kanak dilakukan untuk mengembangkan dan menstimulasi enam aspek perkembangan anak yaitu nilai agama moral, bahasa, fisik motorik, kognitif, sosial emosional, dan seni. Semua aspek perkembangan tersebut distimulasi dengan baik sesuai dengan tahap perkembangan anak.

Masa awal perkembangan, anak bisa memperoleh informasi melalui mendengar dan mengamati. Selanjutnya anak akan mulai belajar membaca untuk memperoleh informasi melalui tulisan. Membaca pada umumnya dikaitkan dengan kemampuan untuk memahami tulisan. Ketika anak belum bisa memahami sebuah tulisan, sering dianggap bahwa anak tersebut belum bisa membaca. Padahal kemampuan membaca pada diri anak dilalui melalui beberapa tahapan. Tahapan membaca pada anak biasanya dimulai dengan membaca fantasi terlebih dahulu hingga mereka dapat membaca dengan lancar. Kemampuan membaca pada anak usia dini dapat distimulasi dengan cara melatih memperdengarkan bunyi huruf, kata-kata tentang benda dan memperlihatkan bentuk huruf dan bendanya (Rasyid, 2010). Guru harus mampu mengevaluasi pembelajaran yang sudah dilakukan, apakah metode yang digunakan pembelajaran berhasil atau tidak. Menurut T. U. Subar Junanto (2019) an educator it is also required to have the skills or skills needed in the education process according to the scientific field. Hal ini berarti guru dituntut untuk mampu mengevaluasi hasil belajar anak didiknya.

Sebagai umat muslim yang beriman, Al-Qur'an menjadi pedoman hidup yang keberadaannya akan menyelamatkan kita saat berada di dunia dan akhirat. Oleh karena itu wajib bagi setiap muslim untuk bisa membaca dan mengamalkan isi dari Al-Qur'an. Peningkatan kemampuan membaca Al-Qur'an merupakan tuntutan mendesak bagi lembaga-lembaga RA/TK saat ini. Menurut Suriah (2018) masalah pokok yang sering dihadapi oleh anak didik adalah lemahnya membaca Al-Qur'an seperti lemahnya anak 
didik dalam mengenal huruf hijaiyah, kesulitan anak dalam membedakan huruf-huruf hijaiyah tertentu, anak-anak kesulitan dalam membedakan panjang pendeknya harokat/tanda baca. Oleh karena itu diperlukan metode yang tepat supaya anak dapat mempelajari Al-Qur'an dengan baik.

Secara prinsip dasar, pengenalan huruf hijaiyah dapat dilakukan dengan berbagai cara, salah satunya dengan memilih dan menerapkan metode yang tepat dalam pembelajaran anak usia dini. Beberapa metode membaca Al-Qur'an yang telah banyak dikembangkan di Indonesia antara lain metode Iqra', metode Tilawati, dan metode AlHusna. Metode Al-Husna salah satu bentuk metode dari metodologi pembelajaran membaca Al-Qur'an dengan mengenalkan huruf hijaiyah yang sesuai kaidah-kaidahnya (Athaillah, 2010).

Setiap metode pembelajaran masing-masing mengedepankan keunggulan dalam mengupayakan pencapaian sasaran yang diyakini oleh setiap pengembangannya (Suprapti, 2013). Metode Al Husna sendiri baru muncul pertama kali di Colomadu Karanganyar pada tahun 2010 oleh Ustadz Tri Wahyudi. Metode ini diperuntukkan untuk semua kalangan, baik anak usia dini, remaja, dewasa dan lanjut usia (manula). Berdasarkan data metode Al Husna dapat meningkatkan kemampuan anak usia dini dalam membaca huruf Hijaiyah. Metode Al Husna memiliki keistimewaan salah satunya adalah berbasis Rasm Utsmani terjaga keaslian sejak jaman dahulu dan merupakan standarisasi dalam penulisan di sebagian besar dunia sekarang ini.

Di tengah masyarakat yang masih abai dalam pengenalan huruf hijaiyah pada anak usia dini, ada salah satu lembaga yaitu KB/TK MTA Jebres yang membuat program pengenalan huruf hijaiyah dengan menggunakan metode Al Husna, sebagai metode yang digunakan oleh guru untuk mengenalkan huruf hijaiyah pada anak usia dini. KB/TK MTA Jebres merupakan salah satu sekolah yang menggunakan metode Al Husna pertama di Surakarta mulai tahun 2015 sampai sekarang. Karena metode tersebut merupaan metode baru dan belum semua lembaga sekolah mengenalnya. Anak-anak dikenalkan dengan huruf hijaiyah menggunakan metode Al Husna. Jilid Al Husna adalah buku pembelajaran membaca huruf hijaiyah yang disusun dalam 4 jilid. Anak membaca jilid Al Husna dua kali dalam seminggu yaitu pada hari rabu dan kamis. Ketika observasi, penggunaan metode AlHusna di TK/KB MTA Jebres dilatarbelakangi oleh minimnya minat orang tua untuk memberikan pembelajaran terkait membaca Al-Qur'an seedini mungkin. Langkah awal agar bisa membaca Al-Qur'an adalah dengan mempelajari huruf hijaiyah. Dalam proses pengenalan huruf hijaiyah pada anak ada beberapa metode yang bisa diterapkan, namun sebagian anak masih ada yang belum mampu menerapkan secara maksimal. Metode $\mathrm{Al}$ Husna dapat menjadi alternatif supaya anak lebih mudah dalam mengenal huruf hijaiyah dan mempelajari Al-Qur'an.

\section{METODE PENELITIAN}

Penelitian ini merupakan jenis penelitian deskriptif kualitatif. Penelitian kualitatif adalah metode (jalan) penelitian yang sistematis digunakan untuk mengkaji atau meneliti suatu objek pada latar alamiah tanpa ada manipulasi di dalamnya dan tanpa ada pengujian hipotesis, dengan metode-metode yang alamiah ketika hasil penelitian yang diharapkan bukanlah generalisasi berdasarkan ukuran-ukuran kuantitas, namun makna (segi kualitas) dari fenomena yang diamati (Prastowo, 2012). Penelitian kualitatif lebih banyak 
mementingkan segi proses dari pada hasil. Hal ini disebabkan oleh hubungan bagianbagian yang sedang diteliti akan jauh lebih jelas jika diamati dalam proses (Moleong, 2012).

Penelitian ini dilakukan di TK/KB MTA Jebres dengan subyek penelitian anak usia 4-5 tahun (TK A) berjumlah 17 siswa. Untuk informan penelitian adalah kepala sekolah KB/TK MTA Jebres, penanggung jawab KB/TK MTA Jebres dan guru kelas TK A. Teknik pengumpulan data menggunakan tiga cara yaitu dengan observasi, wawancara, dan dokumentasi. Wawancara dilakukan guna untuk mendapatkan informasi tentang cara guru mengimplementasikan metode Al Husna kepada anak usia dini. Observasi dilakukan guna untuk mengetahui implementasi di lapangan penggunaan metode Al-Husna. Dokumentasi dilakukan untuk memperkuat informasi atau data yang telah dimiliki dari hasil wawancara dan observasi, dokumentasi yang diambil terkait implementasi penggunaan metode Al Husna dalam pengenalan huruf hijaiyah.

Keabsahan data sangat diperlukan dalam sebuah penelitian. Oleh karena itu, untuk mendapatkan data yang valid perlu teknik pemeriksaan. Ada beberapa teknik yang bisa digunakan diantaranya adalah ketidakseriusan responden, ketekunan pengamat, triangulasi, pemeriksaaan dengan rekan, pemeriksaan saling pengaruh antara subjek, umpan balik informan (Suwartono, 2014). Untuk mendapatkan data yang valid menggunakan teknik triangulasi data. Yaitu memadukan antara hasil dari observasi, wawancara dan dokumentasi sehingga diperoleh data yang benar-benar valid dalam penelitian. Sedangkan untuk analisis data dilakukan dengan cara pengumpulan data, reduksi data, penyajian data hingga penarikan kesimpulan. Analisis data adalah proses mengorganisasikan dan mengurutkan data ke dalam pola, kategori, dan satuan uraian dasar sehingga dapat ditemukan tema dan dapat dirumuskan hipotesis kerja seperti yang disarankan oleh data (Moleong, 2012). Aktivitas dalam analisis data (Moleong, 2012) meliputi 1. Data Reduction (data reduksi). 2. Data Display (penyajian data). 3. Conclusion Drawing/Verification (penarikan kesimpulan/verifikasi).

\section{HASIL DAN PEMBAHASAN}

Metode Al Husna adalah suatu upaya perwujudan pembelajaran membaca AlQur'an yang mudah, praktis, sistematis serta berpedoman pada pengajaran Rasulullah SAW kepada para sahabatnya yaitu dengan memakai penulisan rasm utsmani. Dalam Al Husna terdapat 3 langkah agar dapat mengantarkan peserta didik mampu membaca AlQur'an. Langkah tersebut dilakukan dengan cara anak memperhatikan jilid Al Husna dengan benar kemudian anak memperhatikan guru dalam melafalkan huruf hijaiyah pada jilid Al Husna kemudian anak melafalkan sendiri huruf hijaiyah pada jilid Al Husna dengan benar, langkah tersebut dinamakan Scanning-Story-Saying, peserta didik akan mampu menguasai serta melafalkan seluruh huruf hijaiyah di dalam Al Qur'an dengan cepat, tepat dan benar (Athaillah, 2010). Dalam metode ini sistematika pengajarannya memiliki 4 jilid yang saling berkesinambungan antara satu jilid dengan jilid berikutnya serta memiliki sub bagian masing-masing.

Penyusunan huruf hijaiyah pada jilid Al Husna, yaitu disusun sesuai kesulitan anak dalam pelafalan huruf hijaiyah. Jilid Al Husna disusun tidak urut dari alif sampai $y a^{\prime}$ melainkan disusun sesuai kesulitan-kesulitan yang biasanya dialami anak dalam 
melafalkannya baik bunyi maupun bentuk, dengan seperti itu akan mudah bagi anak untuk mengenal huruf hijaiyah tanpa ada salah dalam pengucapan.

Jilid pertama pada metode Al Husna anak sudah dikenalkan dengan huruf hijaiyah bersambung, sehingga anak dapat terbiasa dari awal menggunakan huruf hijaiyah bersambung melalui pengenalan pada Al Husna jilid awal. Sehingga untuk tahap berikutnya anak sudah terbiasa. Pada pengucapan harokat dalam huruf hijaiyah seperti fathah, kasroh, dhommah guru menggunakan istilah yang mudah dipahami oleh anak, seperti pada saat pengucapan harokat kasroh anak diminta untuk senyum agar memudahkan anak untuk mengingat dalam melafalkan harokat kasroh pada jilid Al Husna.

Pada anak yang mengalami kesulitan dalam pengenalan huruf hijaiyah metode $\mathrm{Al}$ Husna juga menganjurkan supaya selain memberi contoh bacaan dengan mengucap, guru juga dapat mengenalkan huruf hijaiyah dengan menulis ulang huruf hijaiyah yang anak merasa kesulitan dalam mengenal kemudian guru menggunakan istilah-istilah kehidupan sehari-hari. Dengan teknik seperti itu dapat membantu anak untuk lebih mudah mengenal huruf hijaiyah.

Penerapan metode Al-Husna sebagai alternatif dalam pengenalan huruf hijaiyyah dilakukan dengan beberapa tahapan.

\section{a. Persiapan.}

Sebelum proses pembelajaran pengenalan huruf hijaiyah berlangsung, maka diperlukan suatu persiapan yang matang dan terencana agar tujuan maupun target yang telah ditentukan tercapai. Jika persiapan sudah terlaksana dengan baik, maka tidak menutup kemungkinan bahwa pelaksanaan pembelajaran akan berjalan dengan baik dan maksimal. Persiapan yang dilakukan sebelum dimulai pembelajaran yaitu dengan menyiapkan ruang kelas, alat yang akan digunakan untuk pembelajaran dan RPPH.

Menurut Sukmadinata (2015), persiapan berarti kegiatan dari seorang pendidik yang akan mengajar dengan menggunakan media pembelajaran. Persiapan pendidik di KB/TK MTA Jebres antara lain adalah : 1) Membuat indikator, tema, tujuan dan materi pembelajaran sesuai kurikulum; 2) Menyiapkan ruang kelas dengan baik dan bahan-bahan pembelajaran seperti lembar kerja anak, buku, dan lain-lain; 3) Metode dan strategi pembelajaran TK/KB MTA Jebres dalam mengenalkan huruf hijaiyah menggunakan metode Al-Husna.

b. Pelaksanaan.

Pelaksanaan pembelajaran pada umumnya meliputi tiga hal yaitu pembukaan, kegiatan inti dan penutup (Latifah Permatasari Fajrin, 2019). Pelaksanaan pembelajaran adalah proses yang mengandung serangkaian kegiatan antara guru dan anak atas dasar hubungan timbal balik yang berlangsung untuk mencapai tujuan. Kegiatan pembelajaran pengenalan huruf hijaiyah menggunakan metode Al Husna pada semua tingkatan dilaksanakan dengan bimbingan guru yang dilakukan dengan cara mandiri sesuai dengan kemampuan anak. Metode Al Husna menerapkan sistem guru mengajarkan kepada anak dengan memisalkan huruf hijaiyah dengan kehidupan sehari-hari namun apabila anak masih merasa sulit guru menulis ulang huruf hijaiayah tersebut di selembar kertas atau di jilid anak. Apabila anak sudah paham dengan huruf hijaiyahnya maka anak dianjurkan untuk membaca sendiri, dan apabila anak sudah lancar maka lanjut ke halaman selanjutnya tak lupa guru mencatat hasil bacaan anak ke kartu prestasi anak. 
Pelaksanaan pembelajaran dimulai dari persiapan sampai evaluasi. Menurut Rolina (2012) dalam proses pembelajaran meliputi persiapan, pelaksanaan (pembukaan, inti, penutup), dan evaluasi. Adapun tahap pelaksanaan metode Al Husna dalam pengenalan huruf hijaiyah adalah sebagai berikut:

1) Sistem Urutan.

Sistem urutan pengenalan huruf hijaiyah pada metode Al Husna tidak diurutkan sebagaimana biasanya, tetapi diurutkan dengan susunan yang memudahkan anak untuk mengidentifikasi huruf hijaiyah dengan baik dalam posisi sendiri maupun bersambung. Dengan sistem ini diharapkan anak mampu mengenal dan membedakan masing-masing huruf hijaiyah supaya tidak salah dalam mengenal huruf hijaiyah dengan cepat dan mudah. Anak diminta membaca jilid Al Husna dari pojok atas bagian kanan jilid ke bagian kiri dengan urut tanpa dilangkahi dengan penyusunan sesuai dengan kata kunci.

2) Metode Scanning.

Metode Scanning merupakan suatu langkah yang dilakukan dengan cara anak memperhatikan jilid Al Husna dengan benar. Usia dini merupakan usia yang gemar bermain dan aktif untuk melakukan sesuatu, hal ini menjadi tugas guru untuk membuat anak memperhatikan jilid Al Husna dengan tenang agar anak mampu memperhatikan dengan baik. Sebelum anak membaca jilid Al Husna, anak terlebih dahulu memperhatikan serta kata kunci pada jilid Al Husna supaya apa yang dipelajarinya nanti dapat tertanam dengan lebih baik. Anak diminta memperhatikan terlebih dahulu tanpa diberi tahu oleh guru, setelah anak memperhatikan jilidnya kemudian guru langsung memberikan ciri-ciri huruf hijaiyah disertai pengucapan yang benar, setelah itu anak menirukan yang telah diberi contoh oleh guru.

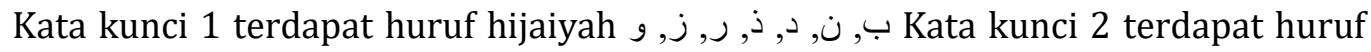
hijaiyah Jata kunci 3 terdapat huruf hijaiyah ل, ك, terdapat huruf hijaiyah ث, ش, س, ص, ض, ط, ط.

3) Menulis.

Menulis merupakan suatu proses kreatif memindahkan gagasan ke dalam lambang-lambang tulisan (Semi, 2007). Anak dapat menyampaikan makna, ide, pikiran dan perasaannya melalui untaian kata-kata yang bermakna. Tahap yang selanjutnya dilakukan setelah bisa membaca huruf hijaiyah adalah dengan menuliskannya agar lebih paham dan hapal betul.

Cara pengenalan huruf hijaiyah menggunakan metode Al Husna yang dilakukan guru adalah dengan menulis ulang huruf hijaiyah yang sedang dikenalkan kepada anak. Guna untuk lebih menanamkan ke memori anak supaya anak dapat mengingat dengan baik. Guru menulis di atas kertas dengan bolpoin/pensil atau bisa juga ditulis di lembar jilid Al Husna yang kosong. Terkadang ada anak yang ikut menulis ulang huruf hijaiyah di atas kertas bahkan anak membuat bentuk-bentuk huruf hijaiyah seperti hewan atau permisalan kehidupan sehari-harinya dan anak lebih mudah mengingatnya.

c. Penilaian

Proses penilaian untuk anak usia dini adalah secara otentik dilihat dari prosesnya bukan hasilnya. Penilaian atau evaluasi merupakan bagian dari kurikulum pendidikan, adanya evaluasi guna mengetahui tujuan dari pendidikan yang sudah direncanakan apakah kegiatan belajar mengajar sudah sesuai atau belum, sedangkan dalam pelaksanaannya yang melakukan evaluasi adalah seorang pendidik (N. A. Subar Junanto, 
2018). Evaluasi ini untuk menentukan apakah pendidikan bisa dilanjutkan, diperbaiki atau dihentikan. Evaluasi menjadi bagian yang tidak dapat dipisahkan dari kegiatan pendidikan. Oleh karena itu, kegiatan evaluasi tidak mungkin dielakkan dalam proses pembelajaran, baik evaluasi hasil belajar maupun evaluasi pembelajaran (L. P. Subar Junanto, 2018). Penilaian yang dilakukan oleh guru KB/TK MTA Jebres dalam pengenalan huruf hijaiyah adalah dengan menulis hasil belajar anak di kartu prestasi anak atau biasa disebut anekdot untuk menandai anak sampai halaman berapa membaca dan melihat kemampuan anak dalam pengenalan huruf hijaiyah menggunakan metode Al Husna. Selain itu pengisian kartu prestasi anak juga guna memberitahukan kepada orangtua mengenai kemampuan anak dalam pengenalan huruf hijaiyah.

Bentuk evaluasi yang lain adalah dengan diberikannya reward. Menurut Purwanto (2011) reward adalah alat untuk mendidik anak-anak supaya anak merasa senang karena perbuatan atau pekerjaannya menadapat penghargaan. Pemberian reward di KB/TK MTA Jebres berguna untuk menambah semangat anak dalam belajar mengenal huruf hijaiyah menggunakan metode Al Husna. Pemberian reward biasanya anak diberi bintang ditangan anak dengan bolpoin/spidol.

Hasil wawancara dengan guru juga menyebutkan bahwa penerapan metode $\mathrm{Al}$ Husna membuat anak-anak semakin antusias dalam belajar, guru semakin mudah dalam mengenalkan huruf hijaiyah. Penerapan pembelajaran serta konsep penyusunan jilid Al Husna yang mudah dipahami siswa mendapatkan respon yang baik dari siswa. Hal ini menjadi keunggulan metode Al Husna dalam pengenalan huruf hijaiayah pada anak usia 45 tahun. Meskipun masih adanya kendala senantiasa perlu adanya upaya untuk mengatasi dan memperbaiki setiap kendala yang muncul baik dari anak maupun dari faktor yang lain. Berdasarkan hasil observasi setelah dilakukan metode Al Husna ditemukan bahwa anak usia dini di KB/TK MTA Jebres sudah bisa membaca huruf hijaiyah dengan baik dan berhasil menghapal pada tiap hurufnya, sedangkan untuk anak yang sudah mampu membaca huruf hijaiyah bersambung dalam tahap awalnya, membuat anak tersebut menjadi tambah semangat mempelajari Al-Husna.

\section{SIMPULAN}

Dari hasil kajian dalam penelitian ini secara keseluruhan dapat diambil kesimpulan bahwa implementasi metode Al Husna dalam pengenalan huruf hijaiyah dalam pelaksanaanya dibagi menjadi 3 tahap, yaitu tahap persiapan, tahap pelaksanaan dan tahap penilaian. Persiapan guru yaitu dengan menyiapkan ruangan, materi dan RPPH sebagai pedoman pembelajaran. Tahap pelaksanaan metode Al Husna melalui 3 proses yaitu dengan sistem urutan, metode scanning dan menulis huruf hijaiyah. Tahap penilaian di TK/KB MTA Jebres dengan mengoreksi proses pembelajaran anak dan dituliskan di lembar prestasi anak berupa anekdot dan pemberian reward berupa bintang yang digambar/ditempel ditangan dengan spidol. Dengan demikian penggunaan metode AlHusna sebagai alternatif pengenalan huruf hijaiyah di TK/KB MTA Jebres dapat berjalan dengan baik. 


\section{DAFTAR PUSTAKA}

Athaillah. (2010). Sejarah Al-Qur'an. Yogyakarta: Pustaka Pelajar.

Hasan, M. (2010). Pendidikan anak usia dini. Jakarta: PT. Indeks.

Latifah Permatasari Fajrin, S. J. (2019). Implementasi pendidikan sex pada anak usia dini. PAUD Lectura, 79-82.

Moleong, L. (2012). Metodologi penelitian kualitatif. Bandung: Remaja Rosdakarya.

Prastowo, A. (2012). Metode penelitian kualitatif dalam perspektif rancangan. Yogyakarta: Ar-Ruzz Media.

Purwanto. (2011). Evaluasi hasil belajar. Yogyakarta: Pustaka Pelajar.

Rasyid. (2010). Minat indikator-indikator minat. Jakarta: Bumi Aksara.

Rolina, N. (2012). Alat permainan edukatif untuk AUD. Yogyakarta: Ombak.

Semi, M. A. (2007). Dasar-dasar keterampilan menulis. Bandung: Angkasa.

Subar Junanto, L. P. (2018). Evaluasi program Standar Kompetensi Lulusan Al Quran (SKL Al Quran) Di Jurusan Pendidikan Islam Anak Usia Dini Fakultas Ilmu Tarbiyah Dan Keguruan IAIN Surakarta Tahun 2017. At Tarbawi, 1-11.

Subar Junanto, N. A. (2018). Evaluasi program pembelajaran di PAUD inklusi dengan model Context, Input, Process, and Product (CIPP). INKLUSI: Journal of Disability Studies, 179-194.

Subar Junanto, T. U. (2019). Evaluation model of expertise practice programs for early childhood educator teachers. Jurnal Pendidikan Anak Usia Dini, 128-142.

Sukmadinata, N. S. (2015). Metode penelitian pendidikan. Bandung: PT Remaja Rosdakarya.

Suprapti, I. M. (2013). Model-model pembelajaran komunikatif dan inovatif. Surakarta: Fataba Press.

Suriah, M. (2018). Metode Yanbu'a untuk meningkatkan kemampuan membaca Al-Qur'an pada kelompok B-2 RA Permata Hati Al-Mahalli Bantul. Jurnal Pendidikan Madrasah, 291-299.

Suwartono. (2014). Dasar-dasar metodologi penelitian. Yogyakarta: CV Andi Offset.

Wiyani, N. A. (2014). Kapita selekta PAUD. Yogyakarta: Gava Media. 